\title{
Healthcare Practitioners and Technical Occupations
}

National Cancer Institute

\section{Source}

National Cancer Institute. Healthcare Practitioners and Technical Occupations. NCI

Thesaurus. Code C97634.

A class of professional or vocational positions of employment that involve healthcare practice or technical operations. 